\title{
A Formação Continuada de Diretoras da Rede de Educação Básica em São José dos Campos-SP
}

\author{
The Continued Training of Directors of the Basic Education Network \\ in São José dos Campos-SP
}

\begin{abstract}
RESUMO Neste artigo, mostra-se uma pesquisa de campo referente à formação continuada de diretoras da rede de ensino em São José dos Campos-SP. Inicialmente, um grupo focal foi realizado com dez gestoras da Educação Básica, que teve por objetivos dar voz aos diretores para exporem opiniões sobre temas como o gerenciamento de conflitos e a presença da formação em seu trabalho. Foram coletados apontamentos da literatura especializada a respeito dos temas discutidos, valendo-nos de reflexões acerca da formação do diretor, e das transformações que redefiniram o seu papel. Explorando o conteúdo discutido no encontro com as diretoras, procurou-se oferecer subsídios para um programa de formação continuada oferecida a essas lideranças.
\end{abstract}

PALAVRAS-CHAVE: DiRETOR ESCOLAR. PAPEL DO DIRETOR. ForMAÇÃo CONTINUADA.

ABSTRACT This article presents a research related to the continuing education of school network directors in São José dos Campos-SP. Initially, a focus group was conducted with ten managers of Basic Education, in which opinions were expressed on topics such as conflict management, and the presence of training in their work. We collected notes from the specialized literature on the topics discussed, using reflections on the director's training, and the transformations that redefined his role. Exploring the content discussed at the meeting with the directors, it was sought to offer subsidies for a continuing training program offered to these leaderships.

KEY-WORDS: SCHOOL DIRECTOR. ROLE OF THE DIRECTOR. CONTINUING EDUCATION.

\section{O ESTUDO SOBRE A FORMAÇÃO DE DIRETORES: UMA LACUNA A SER PREENCHIDA}

mbora os diretores e diretoras ocupem cargos com alto grau de complexidade na equipe pedagógica, são limitadas as reflexões acerca desses atores na literatura da área. Assim, em parte pela "relativa escassez" de estudos nessa temática, mencionada por Paro (2010), elaborou-se esta pesquisa, procurando reconhecer aspectos da realidade local vivenciada por diretoras da rede de ensino de São José dos Campos, município do Vale do Paraíba Paulista - do qual uma das autoras deste artigo tam-

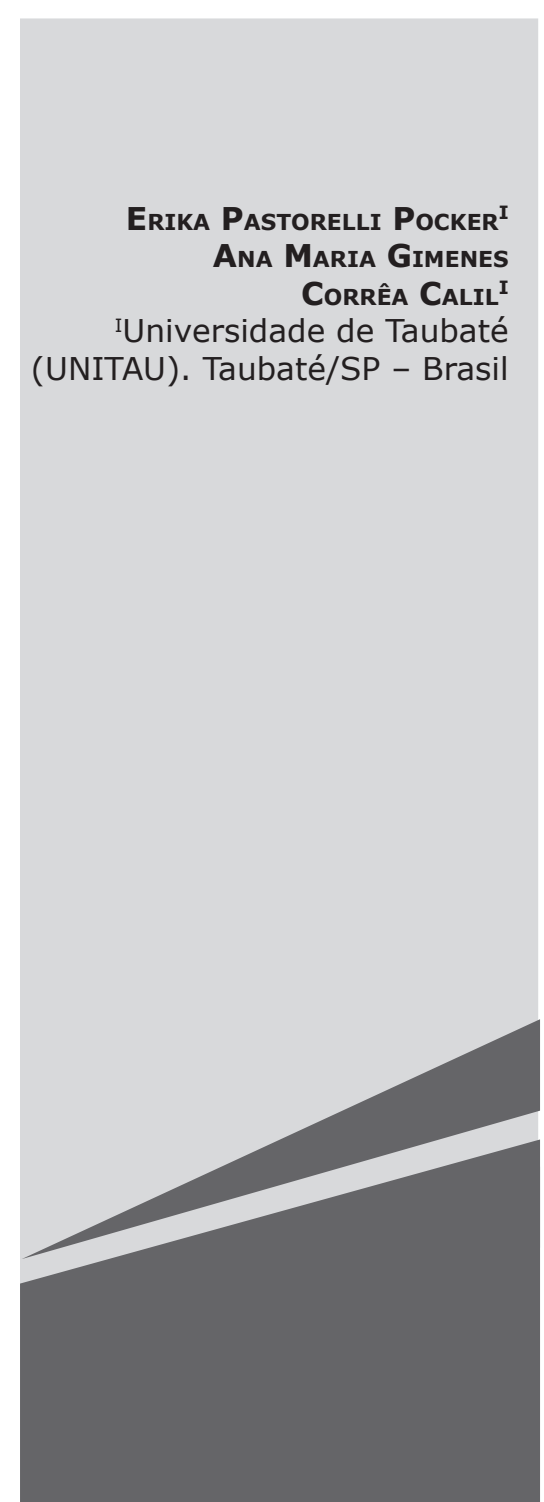


bém faz parte. Por meio de um convite aberto, dez gestoras responderam aos nossos contatos, e fizeram parte de um grupo focal no qual discutimos as práticas de gestão nas escolas, o gerenciamento de conflitos em suas equipes pedagógicas, e os programas de formação continuada dos quais elas participaram.

Em relação às considerações teóricas recolhidas, foram utilizados apontamentos de Fanfani (2001) e Abdian (2013) sobre as transformações sociais que redefiniram o papel do diretor escolar. Recorreu-se também às análises de Libâneo (1998; 2013), que estabelece uma conexão entre o processo de redemocratização do Brasil, a construção de novas políticas educacionais, e a reformulação do perfil esperado dos gestores pedagógicos. Quanto ao tema da formação continuada, no qual um elevado número de produções acadêmicas foi localizado, confronta-se o que foi exposto no grupo focal com as reflexões de autores como Lück (2011), que, após diagnosticar diversos processos de capacitação dos gestores educacionais, pontuou que os conteúdos dos cursos oferecidos a esse público ainda empregavam uma metodologia "conteudista", adotando o ensino pela transmissão de informações, de forma acrítica. A respeito do tema do conflito no ambiente escolar, recorreu-se às produções de Chrispino (2007), Barbosa (2007) e Martins (2016), procurando delinear possibilidades ao diretor na resolução construtiva de tais divergências.

Nesta pesquisa, o grupo focal foi escolhido como técnica de investigação qualitativa, pois esse método, de acordo com Gatti (2012), proporciona ao pesquisador a captura de manifestações da subjetividade dos participantes que, em outras formas de investigação, não se dariam de forma clara. A pesquisadora afirma que o grupo focal possibilita a reflexão sobre pontos de vista emocionais ancorados na experiência cotidiana dos participantes, com a obtenção de quantidade substancial de material para análises em curto período. Por sua vez, Vergara (2004) expõe o grupo focal como o instrumento apropriado quando o objetivo da pesquisa reside na explicação da forma como as pessoas consideram uma experiência, um evento ou uma ideia - pois esse método pode fornecer informações enriquecedoras acerca do que os participantes do estudo sentem, pensam ou, ainda, a respeito da forma como agem em relação ao tema pesquisado.

Contudo, para que este instrumento seja eficaz, Gatti (2012) aponta que o moderador ou facilitador deve conduzir a discussão sem interferências indevidas, não oferecendo opiniões particulares ou conclusões; dessa forma sua condução deve favorecer efetivamente a discussão coletiva. O moderador precisa ter em mente que não está fazendo uma entrevista, e sim criando condições para que os participantes atuem, efetivamente, nas reflexões desencadeadas em grupo.

Para o início da pesquisa, após quatro meses de contatos e desencontros - o que ressalta a dificuldade dos envolvidos na reflexão sobre seu próprio "fazer pedagógico" realizamos um grupo focal, em abril de 2016, com dez diretoras da Educação Básica do município de São José dos Campos-SP, as quais aceitaram participar do estudo, sendo-lhes garantido o sigilo de sua identidade, pela assinatura de um Termo de Consentimento. No quadro seguinte, detalham-se as regiões da cidade em que atuam, bem como, o seu tempo de trabalho na direção escolar.

Para a realização do grupo focal, estruturou-se um roteiro prévio de perguntas, composto por perguntas abertas, pelas quais se buscou obter informações sobre as necessidades formativas dos diretores, entre outros assuntos, no gerenciamento de conflitos em ambientes escolares. A discussão foi desencadeada por questões "disparadoras", as quais propiciaram relatos cujos conteúdos foram posteriormente agrupados em unidades de análise para estruturar esta pesquisa. Desse modo, nesse grupo focal verificou-se concepções das diretoras a respeito do seu papel na gestão das relações interpessoais no ambiente escolar, permitindo uma análise da forma como concebem seu trabalho pedagógico em equipe, identificando metodologias adequadas para a sua formação continuada. 
Quadro 1 - Diretoras Participantes do Grupo Focal

\begin{tabular}{|l|l|l|}
\hline Participante & Região & Tempo de trabalho na direção escolar \\
\hline D1 & Centro & 19 anos na direção -6 anos na escola atual \\
\hline D2 & Centro & 12 anos na direção -1 ano e 6 meses na escola atual \\
\hline D3 & Sul & 2 anos na direção -1 ano na escola atual \\
\hline D4 & Centro & 16 anos na direção -2 anos na escola atual \\
\hline D5 & Sudeste & 5 anos na direção -3 anos na escola atual \\
\hline D6 & Sul & 19 anos na direção -3 anos na escola atual \\
\hline D7 & Leste & 12 anos na direção -9 anos na escola atual \\
\hline D8 & Sudeste & 6 anos na direção -5 anos na escola atual \\
\hline D9 & Leste & 16 anos na direção -2 anos na escola atual \\
\hline D10 & Centro-Oeste & 2 meses na direção -5 anos como coordenadora \\
\hline
\end{tabular}

(Elaboração das autoras do artigo)

Tabela 1: Artigos recuperados por assunto, nos Periódicos de Qualis A1, A2, B1 e B2 (Pesquisa limitada ao período 2000-2016)

\begin{tabular}{l|l|l|l|l}
\hline \multirow{2}{*}{ PERIÓDICOS } & \multicolumn{4}{l}{ ASSUNTO } \\
\cline { 2 - 6 } & $\begin{array}{l}\text { Formação } \\
\text { Continuada }\end{array}$ & \multicolumn{2}{l}{ Diretor Escolar } & \multicolumn{2}{l}{ Gestão Escolar } & $\begin{array}{l}\text { Conflitos } \\
\text { na Escola }\end{array}$ \\
\hline A1 (8 no total) & 17 & 6 & 1 & 3 \\
A2 (3 no total) & 5 & 7 & 1 & 2 \\
B1 (11 no total) & 18 & 5 & 4 & 6 \\
B2 (9 no total) & 9 & 5 & 4 & 3 \\
\hline Total de artigos & 49 & 23 & 10 & 14 \\
\hline
\end{tabular}

(Elaboração das autoras do artigo)

\section{O OLHAR DAS DIRETORAS SOBRE SUA FORMAÇÃO CONTINUADA E OS DIAGNÓSTICOS ACERCA DO TEMA}

Para a análise do conteúdo das discussões, após a procura em cerca de 30 periódicos listados na área de educação com os Qualis A1, A2, B1 ou B2, ${ }^{1}$ recuperaram-se 96 artigos, dos quais 20 foram utilizados como referências. A Tabela 1 permite verificar a in-

1 Pesquisa previamente realizada no site do Qualis da CAPES: http://qualis.capes.gov.br, e complementada visitando os sites dos periódicos nacionais sobre educação relacionados. Ressalta-se que, neste artigo, apenas algumas referências foram inseridas neste trabalho. cidência de periódicos pré-selecionados de acordo com o Qualis, e o número de artigos recuperados divididos em quatro temáticas de apoio - que foram por sua vez as palavras-chave pesquisadas no campo assunto do site de cada revista, a saber: "formação continuada"; "diretor escolar"; "gestão escolar" e "conflitos na escola".

Pela visualização do Gráfico 1, que expõe visualmente a porcentagem de artigos por tema, pode-se perceber a presença acentuada de artigos sobre o tema da Formação Continuada. Em relação a produções a respeito dos diretores de escola e/ou acerca da gestão desses espaços, verifica-se uma incidência 
muito limitada de reflexões em relação a esses temas, tendo em vista a amplitude do conteúdo recuperado: para um intervalo de 16 anos, em uma pesquisa envolvendo 31 periódicos, houve cerca de 33 artigos recuperados nesses assuntos.

Gráfico 1: Porcentagem dos artigos recuperados por assunto e Qualis das publicações (Pesquisa limitada ao período 2000-2016)

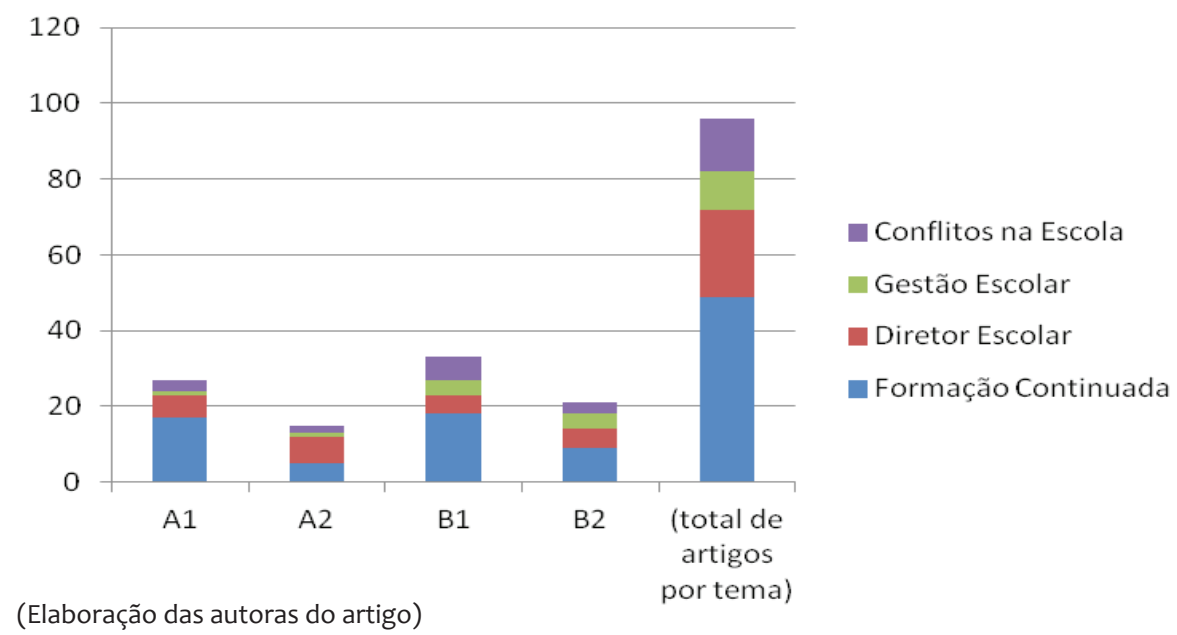

Esses dados comprovam a afirmação de Paro (2010, p. 766), para quem, no campo da gestão escolar, "[...] o que surpreende não é a existência do discurso que valoriza a figura do diretor, mas a relativa escassez de estudos e pesquisas a respeito da natureza e do significado das funções do diretor de escola à luz da natureza educativa dessa instituição".

Em relação ao conteúdo coletado nos depoimentos das diretoras, para facilitar o diálogo entre o material colhido no grupo focal e as referências de especialistas sobre os temas discutidos, estruturou-se o trabalho em cinco unidades de análise: "Conflito Escolar"; "Transformações sociais e o papel do diretor”; "Panorama local do diretor”; “Formação continuada e desenvolvimento de competências" e "Instâncias de Articulação na Secretaria Municipal de Educação”, procurando, com essas categorias, estabelecer um ordenamento lógico na construção da pesquisa.

Assim, com as respostas ao primeiro questionamento, sobre o entendimento das diretoras quanto ao "Conflito Escolar", a pesquisadora obteve considerações que, de maneira geral, revelaram uma concepção comum, apesar das diferenças nas experiências e localidade, ou seja: conflito escolar "é todo atrito que ocorre na escola"; tal definição da participante D1 foi amplamente aceita pelo grupo. Essa concepção valida a observação de Chrispino (2002), segundo a qual a divergência de opiniões que caracteriza a existência de conflitos acontece entre alunos e professores, bem como entre esses atores em seu próprio conjunto, no ambiente escolar. O conflito configura-se assim como "parte integrante da vida e da atividade social”, sendo originado de diferentes interesses e aspirações. O autor ressalta que não se deve refletir somente na questão do erro e do acerto das partes em conflito, devendo-se observar antes de tudo os argumentos pelos quais as diferentes posições são expostas em relação umas às outras. Ainda acerca desse aspecto, Martins (2016, p. 573) indica que:

Relações de conflito existem quando diferentes concepções e/ou ideias de ciência, de sociedade, de 
educação, de política são debatidas, constituindo-se como situações de aprendizagem se forem bem dialogadas e negociadas entre indivíduos e grupos, de forma aberta e transparente. Nessa perspectiva, é preciso compreender as opiniões/ posturas diferentes para que não haja manipulação de interesses.

Por sua vez, a participante D4 ampliou a concepção sobre o conflito, acrescentando o contexto social e familiar onde ele se forma:

Para mim conflito escolar acontece porque existe o conflito do ser humano: onde tem ser humano, tem conflito. Dentro dos muros da escola, falo que são as muitas educações dadas em casa, reunidas num só lugar e cada um partilha da educação que recebeu em casa - ou não. Quando se entra no muro da escola, na sala de aula com 25 ou 30 alunos, cada um com um tipo de educação, com formações em contextos familiares diferente [...] aí surge o conflito!

Em uma análise sobre essa discrepância de culturas, Barbosa (2007, p. 1062) nota que, embora seja possível verificar movimentos para a apropriação da cultura escolar pelas famílias, "a escola segue desconhecendo as culturas familiares". O autor aponta que a escola, por meio de sua equipe pedagógica, deve procurar apreender os modos de socialização nas famílias para os quais possa articular propostas e práticas visando a inclusão e o desenvolvimento das crianças, criando um projeto na escola conectando "as fronteiras das culturas familiares e das culturas escolares" (IDEM, p. 1063). Nesse âmbito, Martins (2016) afirma que as escolas precisam desempenhar um papel de mediação entre as suas comunidades, e, sobretudo os gestores e demais membros da equipe poderiam compreender melhor os dilemas trazidos pelos alunos, "construindo um ambiente coletivo de apoio para evitar/ superar sentimentos de marginalização e insegurança no espaço escolar" (IDEM).

Ainda com relação às famílias, a participante D6 citou que o conflito também acontece "com os pais que já chegam muito bravos, ameaçando o professor, o diretor, querendo ir para a delegacia de ensino". Nesse quadro, o(a) diretor(a) necessita verificar, na medida do possível, as diferenças e particularidades das famílias que compõem a comunidade escolar, buscando uma forma de agir na qual possa, ainda que de forma limitada, diagnosticar o surgimento das situações de violência. As participantes D2, D3 e D10 ressaltaram que a questão da intolerância na sociedade como um todo interfere no cotidiano da escola. Citando D3:

O conflito social é reflexo dos conflitos que a gente vive na sociedade, é tudo que acontece dentro dos muros das escolas - nisso está respingando o que a sociedade vive. Uma sociedade intolerante, que às vezes se porta como sujeitos de direitos, esquecendo as suas responsabilidades [...].

Percebe-se que o processo de construção de identidade do diretor é dinâmico, e tanto o profissional como a comunidade escolar devem estar preparados para constantes mudanças. A inversão de papéis, devido a uma comunidade questionadora, gera uma sobrecarga de trabalho ao diretor, pois é depositada nele uma responsabilidade ímpar, na qual ele tem que sanar os conflitos a qualquer custo ou maneira.

Em outra perspectiva, Fanfani (2007) entende que os jovens, antes de ingressarem na escola são capazes de produzir e refletir por si próprios, sendo portadores de conhecimentos e comportamentos que podem entrar em conflito com a cultura da escola nas quais se inserem. De acordo com o pesquisador, enquanto a escola e sua configuração atual encontram-se pouco flexíveis a transformações 
profundas, as culturas juvenis são instáveis e fragmentadas e pertencem a uma concepção de mundo diferente. Complementando essa discussão, o autor pontua que a diversificação de funções atreladas às escolas não foi correspondida pelo aumento da qualidade e dos recursos que ela mantém. A consequência desse quadro foi "uma decepção e o desencanto social a respeito das escolas e uma profunda sensação de mal-estar no corpo docente que percebe não poder estar à altura das circunstâncias" (p. 337). Na atualidade, portanto, a sociedade tende a esperar mais do que a escola pode oferecer, gerando assim um conflito de expectativas envolvendo a potencialidade e a realidade desses espaços educativos. No caso da figura do diretor escolar, essa situação também é crítica, pois ele, ao concentrar um poder que lhe é inerente por ser funcionário do Estado, deve cumprir "condutas administrativas nem sempre coerentes com objetivos autenticamente educativos", encontrando "condições materiais de realização que não lhe são satisfatoriamente providas quer pelo Estado, quer pela sociedade de modo geral", conforme pontua Paro (2010, p. 770).

Em relação à segunda categoria, sobre as "Transformações sociais e o papel do diretor", os relatos das participantes foram unânimes em revelar que os(as) diretores(as) têm sua figura cada vez mais desvalorizada, sendo que, como destaca D6, esses atores encontram-se muitas vezes isolados em seus espaços de atuação profissional:

Dez anos atrás quando assumimos a liderança tínhamos um perfil onde os professores nos viam como liderança. Hoje não é, e raramente nos veem como parceiros de trabalho - alguns nem isso. O que acontece? Eles nos olham como se na verdade a gente estivesse ali apenas ocupando um cargo.

Esse depoimento vai ao encontro ao que Abdian (2013), em pesquisa sobre a fun- ção do diretor na escola pública no Estado de São Paulo, cita, como um problema a ser enfrentado, a excessiva cobrança pelos órgãos oficiais de educação por índices relativos ao desempenho acadêmico em avaliações externas, que acaba por "subtrair ainda mais do restrito tempo (dos diretores) restante para organizar o trabalho pedagógico e as oportunidades coletivas de diálogo, participação e decisão (p. 980)" - o que também se pode comprovar pela demora no contato efetivo com as diretoras participantes do grupo focal.

Por sua vez, Fanfani (2007) afirma que as instituições educativas devem notar as transformações sociais que têm um acentuado impacto na vida cotidiana do corpo docente, transformando seus dispositivos, em especial aqueles que regulam as relações de autoridade entre professores, diretores e alunos, e os que estruturam os processos de tomada de decisão. Deve-se reconhecer que os adolescentes e jovens têm direitos específicos - à identidade, à expressão de opiniões, ao acesso à informação, à participação na definição e à aplicação das regras que organizam a convivência escolar - e à construção dos mecanismos institucionais, que garantem que o seu exercício deve ser feito de forma plural.

A crise dos valores sociais é outro elemento importante a ser considerado, pois influencia no cotidiano escolar, alterando e interferindo no próprio clima escolar, cenário que precisa ser considerado como um pano de fundo no qual o profissional que ocupa o cargo de diretor deve construir seu trabalho. O pensamento reflexivo sobre o poder de suas ações na concepção de uma educação emancipadora é um fator a ser considerado na formação dos profissionais que ocupam a direção de uma escola. Libâneo (1998, p. 12), sobre essa questão, afirma que:

O local de trabalho e as situações de trabalho têm um potencial formativo. Os profissionais que trabalham na escola aprendem através da organização escolar. A organização escolar também aprende, mudando 
junto com seus profissionais. Então, a ideia chave é esta: os indivíduos e os grupos mudam, mudando o próprio contexto em que trabalham. Há riscos? Tudo depende de uma concepção de projeto pedagógico seguro, realista. $O$ projeto terá um conteúdo político forte, seja à direita, seja à esquerda. Autonomia absoluta é ilusão. Penso que o trabalho coletivo será bem representado no projeto pedagógico se as escolas derem conta de pensar junto e organizadamente: princípios comuns, objetivos comuns, sistema e práticas de gestão negociadas, unidade teórico-metodológica do grupo de professores e diretoria, e um sistema explícito e transparente de avaliação do projeto.

Prosseguindo à análise, em relação à terceira categoria, "Panorama local do diretor", na fala da participante D2, percebeu-se que, ao menos na rede municipal pesquisada, vivencia-se a alta rotatividade da sua equipe, pois as escolas recebem novos profissionais que substituem àqueles que se aposentam ou, simplesmente, novas figuras que aparecem no ambiente diante da necessidade como professores eventuais, agentes educadores e outros, conforme a demanda. Parte considerável desses atores não constrói uma trajetória na unidade, devido ao exercício de suas funções ocorrerem de maneira temporária, gerando assim uma falta de vínculo profissional, de acordo com D2:

É difícil criar um grupo que vista a camisa, e os professores que estou recebendo são professores que estão se aposentando. Chegam à escola, trabalham um ano ou seis meses, se aposentam e não criam vínculo. Assim eu não vou ter um grupo que se fortaleça... Já os agentes ficarão, construirão uma história. Precisamos criar vínculos, pois se não criarmos fica difícil.
Assim, o município de São José dos Campos, reconhecido como um importante polo de tecnologia aeronáutica na América Latina, concentra centros de ensino e pesquisa relevantes nessa área e conta com 149 unidades escolares $^{2}$ (apresentando desse modo, entre diretores e vice-diretores uma população composta por cerca de 300 profissionais) e possui cerca de 60 mil alunos matriculados na educação básica, necessita criar uma política de continuidade para tais agentes educacionais, fomentando a realização de concursos a fim de efetivá-los nessa rede, não os contratando somente por períodos temporários, permitindo a criação de vínculos de longa duração.

Em outro depoimento, uma das gestoras salientou que a trajetória dos(as) diretor(as) obedecia a um processo mais complexo, sendo que esses agentes eram melhor preparados para desempenhar suas funções, de relativa complexidade. De acordo com D4:

Estamos passando por uma realidade atípica na rede - a renovação da nossa mão de obra. Existem no momento atual aposentadorias de professores, diretores, orientadores e supervisores de dentro da secretaria. Dentre deste contexto, a rede antigamente era mais coesa e não existia a hipótese do diretor chegar sem treinamento. Existiam etapas... O professor não saía da sala de aula e já assumia a direção como acontece hoje. Na primeira etapa havia o projeto da creche domiciliar: entrávamos num treinamento, aprendíamos todos os esquemas lá. Esta dificuldade que as novas diretoras sentem nós não sentimos. Porque tínhamos um caminhar na secretaria, participávamos das formações com as diretoras mais experientes, sabíamos onde procurar apoio na secretaria só depois que poderíamos assumir a direção. Não lidávamos di-

2 De acordo com informações da Secretaria Municipal de Educação: http://desjcampos.educacao.sp.gov.br 
retamente com uma escola, mas a creche nos preparava como um estágio. Agora com as demandas de aposentadorias, uma renovação que o sistema não dá conta, não prepara e não forma. Antes eram quarenta diretoras velhas para cinco novas. Hoje é o inverso [...].

Dialogando com Fanfani (2007), deve-se considerar que o desempenho profissional da classe docente tem uma dimensão coletiva, e assim como se fala de um "profissionalismo democrático" para se referir ao trabalho pedagógico, deveria ser pensada a ideia de um "profissionalismo coletivo" para se referir à postura no exercício das profissões contidas nessa área. Dessa forma, a responsabilidade pelo ato educativo deixaria de ser individual, gerando um verdadeiro fortalecimento institucional. Para isso, a criação de vínculos só pode acontecer quando o corpo docente e a equipe de gestão desses espaços puderem efetivamente criar uma trajetória nos seus ambientes educacionais - o que as diretoras da rede local, apontam como algo a ser enfrentado pela gestão municipal.

A participante D5 falou sobre dificuldades encontradas com a migração dos professores locais do Ensino Fundamental para a Educação Infantil, pois o diretor enfrenta nesse processo uma mudança pessoal de cada profissional quanto às suas crenças e ações pedagógicas, interferindo em práticas e relações construídas pela equipe no cotidiano escolar. Citando D5:

Como a D2 falou: não tem uma história na escola, não tem vínculo. Fora os professores do fundamental - tenho recebido muito - que acham que a educação infantil é cheia de frescura. Explico que não é frescura, é a característica da educação infantil, a criança é menor e requer cuidados diferenciados.

Recorrendo a Libâneo (1998), o impacto das transformações no sistema de ensino e nas escolas alterou o perfil de formação geral e profissional dos alunos, propiciando mudanças nos currículos e nas formas de gestão da escola, com a reavaliação das funções e responsabilidades do professorado, e das formas de participação de famílias no processo educacional. $O$ autor define a escola como um espaço social, no qual se compartilham valores, conhecimentos e as capacidades de percepção intelectuais, afetivas e estéticas são desenvolvidas, onde se fomenta a criação de competências para a participação na vida social como um todo, partilhando noções econômicas, sociais e culturais; a escola se configura como um ambiente onde as ações coletivas a transformam e absorvem sua própria transformação. Para o pesquisador, a escola deve atuar como "[...] um lugar de síntese entre a cultura experienciada que ocorre na família, nos grupos de vizinhança, na cidade e a cultura formal, os conteúdos, o ensino" (LIBÂNEO, 1998, p. 10) algo que nos moldes atuais acontece de forma desconexa. Torna-se assim uma tarefa dos educadores contextualizar e problematizar conhecimentos concebidos no espaço fora da escola, conectando-se com eles, de forma crítica e enriquecedora.

$\mathrm{Na}$ quarta categoria, "Formação continuada e desenvolvimento de competências", verificou-se que as profissionais enxergavam na capacitação contínua uma oportunidade para realizar o planejamento adequado de suas atividades, permitindo o aprendizado de estratégias na qualificação do projeto pedagógico escolar. Nesse aspecto, Libâneo (2013, p. 12) pontua que a formação continuada pode "[...] possibilitar a reflexividade e a mudança nas práticas docentes, ajudando professores e diretores a tomar consciência das suas dificuldades, elaborando formas de enfrentá-las".

Sobre as formações previamente oferecidas pela Secretaria Municipal de Educação, algumas das participantes relataram que a prefeitura inclusive já se preocupou com a questão do conflito no ambiente escolar, ao organizar um curso sobre o conceito da "Cultura da Paz". De acordo com a gestora D2, no 
entanto, o curso apresentava limites quanto à sua aplicabilidade:

Concordo com D9 - quando colocam a gente no curso de cultura da paz é para trabalhar dentro da unidade. Só que acho perigoso, abre-se questões emocionais que podem não ser fechadas, e isso é trabalho de terapia, de psicólogo... meu medo é que nos grupos da cultura da paz se abra algo, uma ferida que não estaremos habilitados para fechar.

Em uma análise sobre programas de formação continuada oferecidos no plano nacional e estadual, Lippi \& Neira (2013, p. 80) verificaram que as pesquisas e estudos sobre a formação contínua de professores indicam que as práticas nesse sentido antes marcadas pela realização de "programas de curta duração, em forma de treinamento", ao final do século $X X$, incorporaram "o paradigma reflexivo, focado na relação complexa entre educação, universidade e sociedade do conhecimento" nos últimos anos. Embora esse aspecto positivo seja apresentado, quanto ao quadro específico do Estado de São Paulo, os autores delimitam que:

Entre 1995 e 2006, a política de formação contínua da Secretaria de Educação abrangeu cursos estanques, fragmentados e desarticulados. [...] O que se pode aludir, no máximo, é a incorporação de conhecimentos descontextualizados pelos participantes ou a promoção de reflexões pessoais sobre a prática pedagógica. Como se a solução dos problemas enfrentados no cotidiano pudesse emanar dos indivíduos, ao invés de construir-se por meio do debate coletivo e democrático. A formação reflexiva centrada exclusivamente na própria prática desvia o foco dos obstáculos estruturais engendrados pelas desigualdades sociais, econômicas, políticas e culturais.

No mesmo artigo, Lippi \& Neira (2013) estabelecem "dois ciclos" nas políticas de formação contínua, no Estado de São Paulo. Segundo os autores, o primeiro ciclo, que engloba o período de 1983 a 1994, teve como característica principal a tentativa de superação de modelos gestados pelos governos ditatoriais, e o segundo, entre 1995 e 2006, caracterizou-se pela crescente conexão de práticas afeitas ao "ideário neoliberal". Ainda assim, os autores apontam que "sobram razões para afirmar a existência de um continuum nas ações formativas", pois as evidências coletadas puderam indicar a "centralização das decisões, iniciativas episódicas, ausência de canais de diálogo com os profissionais da educação e a falta de criticidade com relação à tarefa educacional” (p. 89). Assim, enquanto:

No primeiro ciclo, fortemente influenciado pelo debate democrático, as políticas mostraram-se rarefeitas e descontínuas, o que dificultou a consecução de ações que poderiam interferir na formação de professores engajados com a melhoria do processo de ensino-aprendizagem e com a construção de currículos democráticos, no segundo ciclo, marcado pelo ideário econômico, as iniciativas foram permeadas pela racionalização dos recursos, potencializada pelo discurso fazer mais por menos, e pelo foco no mercado de trabalho. Privilegiou-se o caráter técnico, valorizando-se a transposição de conhecimentos produzidos fora da escola (LIPPI; NEIRA, 2013, p. 89/90).

Para a superação de ambos os modelos citados, desconectados da realidade local das escolas e das práticas dos profissionais da educação, faz-se necessária a concepção coletiva de programas de formação continuada 
a esse público, os quais devem ser constantemente avaliados tendo em vista sua aplicabilidade e pertinência, entre outros aspectos.

Prosseguindo, em relação à quinta categoria - sobre as "Instâncias de articulação na Secretaria Municipal de Educação” - a participante D4 relembra como eram as formações na rede, e como o quadro atual é problemático, tendo em vista a ausência de momentos para o diálogo sobre as práticas de gestão escolar no município:

Não estamos tendo o momento de reflexão para voltar para ação, e isso tem embolado o meio de campo - aí a gente começa a atropelar o andamento das coisas. Eu acredito que realmente este momento de reflexão da prática está faltando $e$ que era muito bem estabelecido na rede. Antes tínhamos formações $e$ passamos por diversas experiências como o Progestão. A todo momento refletíamos sobre a prática. Neste momento só estamos aplicando, aplicamos um terço da carga horária, e não refletimos sobre ela. Então o que acontece? A demanda de mães sempre existiu só que agora está nos consumindo porque não estamos dando conta da reflexão que precisa acontecer.

É importante citar que foi inaugurado na cidade o Centro de Formação do Educador (CEFE) "Professor Leny Bevilacqua", 3 que concentra as atividades de formação continuada para educadores e diretores. Aberto, em 2012, para que pudesse servir como um verdadeiro laboratório de ideias aos gestores e demais componentes da equipe pedagógica, com 14 mil metros de área construída, seu prédio conta com dez salas de formação didática, dois laboratórios, três oficinas, um auditório com 250 lugares, e outros três auditórios menores. Configurou-se como um local

3 Site oficial do CEFE: http://www.sjc.sp.gov.br/ secretarias/educacao_cidadania/cefe.aspx adaptado para múltiplas atividades realizadas nos processos de formação continuada, onde deveriam ser promovidas atividades de interação entre formadores - seja em situações de análise de práticas, em debates e seminários - entre outras ações. O CEFE, se potencialmente utilizado, articula-se com o que Libâneo (2013, p. 190) cita:

Seria desejável que as instituições de formação de professores e as delegacias de ensino criassem, na sua estrutura organizacional, algo como um Centro de Apoio à Formação Continuada. Esse centro, além de receber professores da rede de escolas para atividades de formação e capacidade dentro do espírito de associar práticas formativas aos contextos reais de trabalho, ofereceriam não apenas orientação profissional (cursos, debates, oficinas), mas também recursos materiais para vídeo e cinema, computadores, rede Internet e etc. A manutenção desse Centro poderia ter apoio financeiro das Secretarias de Educação estaduais e municipais mediante convênios de parceria, já que a rede pública de ensino seria a mais beneficiada. Iniciativas como essa contribuiriam para resolver a sempre difícil alternância entre a formação teórica e a experiência em situação real (estágios e as práticas reflexivas).

Quando finalizou-se o grupo focal, ao solicitar que as participantes sugerissem algo para as suas próximas formações, D4 assinalou a ausência de reflexão sobre as práticas específicas desempenhadas pelos gestores da rede municipal de ensino:

Se tivesse que sugerir uma formação, seria um momento de reflexão sobre nossas ações. A formação é muito ampla e cada um tem uma realida- 
de específica, então não tem como alinhar exatamente a formação. Mas sobre o aspecto da reflexão, aí sim. Durante esses últimos dez anos não tivemos experiências, trocas, formações. Perdemos este espaço em detrimento dessas novas demandas... Hoje sentimos essa falta!

Assim, o grupo focal ocorreu em um clima de comprometimento e participação entre as diretoras voluntárias que opinaram sobre o assunto. As gestoras questionaram o porquê desta pesquisa não ser realizada e proposta pelas chefias superiores. Elogiaram a iniciativa, reforçando que estariam dispostas a continuar esse diálogo, após os devidos encaminhamentos desta pesquisa. A seguir, temos as considerações finais.

\section{PERSPECTIVAS PARA $O$ FORTALECIMENTO DA FORMAÇÃO CONTINUADA DE DIRETORES}

Com a pesquisa resumida neste artigo, a construção de um programa efetivo de formação continuada para os(as) diretores(as) da rede municipal de ensino revelou-se necessária. Os resultados indicam que esses(as) agentes, embora tenham no Centro de Formação do Educador (CEFE) um espaço possível para esse diálogo de troca de experiências e práticas, ao longo dos últimos anos não foram incentivadas(os) ao convívio com seus pares para a construção de seus projetos pedagógicos. Entre outros fatores, prevaleceu o tempo limitado para atividades de reflexão a respeito do seu próprio agir, o que impossibilita o intercâmbio entre as equipes gestoras da rede municipal. Algumas observações de Lück (2011) a serem levadas na formulação de programas de formação continuada de gestores escolares, e que dialogam com o que foi observado, indicam as seguintes necessidades:
- Estabelecimento de estreita articulação entre Secretarias e Universidades formadoras de docentes e gestores escolares, de modo a pautar as instituições formadoras das necessidades reais de trabalho dos diretores (criando uma articulação entre teoria e prática);

- Definição de programas consistentes e globais de capacitação, centrados em desenvolvimento de competências para o enfrentamento dos desafios de gestão escolar para a orientação da capacitação continuada e em serviço de diretores;

- Adoção de metodologia diversificada na capacitação em serviço e continuada dos diretores, envolvendo coaching e mentoria por profissionais mais experientes, visitação técnica às escolas e observação de outras experiências, oficinas de desenvolvimento de habilidades, mediante simulações de casos e estudo de práticas de sucesso.

Como última colocação, percebeu-se, entretanto, por parte das diretoras, um atrelamento da formação somente aos cursos e demais oportunidades de capacitação que a rede municipal de ensino venha a fornecer. Nenhuma diretora pesquisada demonstrou interesse em buscar qualificação fora de seu horário de trabalho, em uma postura proativa. Nesse ponto, nota-se um movimento de baixa procura autônoma pela resolução de seus problemas, o que indica a necessidade de uma nova postura frente às demandas cada vez mais urgentes na criação de uma identidade fortalecida e renovada do gestor escolar.

Esperamos, por fim, que mais reflexões sobre o tema da gestão escolar, envolvendo as figuras dos diretores e diretoras, sejam realizadas, levando em consideração suas práticas e a teoria - ainda que limitada - acerca de tal campo, e que programas de formação continuada a esse público sejam fortalecidos, e criados nos diferentes âmbitos governamentais, os quais possam efetivamente dialogar com as reais necessidades desses agentes. 


\section{REFERÊNCIAS}

ABDIAN, G, Z. et al. Função do Diretor na Escola Pública Paulista: mudanças e permanências. Educação \& Realidade, p. 977-998, jul./set. 2013.

BARBOSA, M. C, S. Culturas escolares, culturas de infância e culturas familiares: as socializações e a escolarização no entretecer destas culturas. Educação \& Sociedade, v. 28, n. 100, p. 1.0591.083 , out. 2007.

CHRISPRINO, A; CHRISPRINO, R. S. P. Políticas educacionais de redução da violência: mediação do conflito escolar. São Paulo: Biruta, 2002.

FANFANI, E. Considerações sociológicas sobre profissionalização docente. Educação \& Sociedade. Campinas, v. 28, n. 99, mai./ago. 2007.

GATTI, B. Grupo Focal na pesquisa em ciências sociais e humanas. Brasília: Liber Livro, 2012.

LIBÂNEO, J. C. Perspectivas de uma pedagogia emancipadora face às transformações do mundo contemporâneo. Pensar a Prática, v. 1, n. 1, p. 1-21, jan./jun. 1998.

. Organização e Gestão da Escola: teoria e prática, 6. ed. rev. e ampl. São Paulo: Heccus, 2013.

LIPPI, B. G.; NEIRA, M. G. A formação de professores na rede estadual paulista entre 1983 e 2006: uma análise crítica. Educação: Teoria e Prática, v. 23, n. 43, p. 76-92, mai./ago. 2013.

LÜCK, H. Práticas de seleção e capacitação de diretores escolares adotadas por secretarias estaduais e municipais de educação. São Paulo: Centro de Desenvolvimento Humano Aplicado (CEDHAP); Fundação Victor Civita, 2011.

MARTINS, A. M. et al. Mediação de conflitos em escolas: entre normas e percepções docentes. Cadernos de Pesquisa, v. 46, n. 161, p. 566-592, jul./set. 2016.

PARO, Vitor Henrique. A educação, a política e a administração: reflexões sobre a prática do diretor. Educação e Pesquisa, v. 36, n. 3, p. 763-778, set./dez. 2010.

VERGARA, S. C. Projetos e relatórios de pesquisa em administração, 5. ed. São Paulo: Atlas, 2004.

\section{SITES CONSULTADOS}

Listagem do Índice Qualis da CAPES: http://qualis.capes.gov.br

Site oficial da Secretaria Municipal de Educação de São José dos Campos: http://desjcampos. educacao.sp.gov.br

Site oficial do Centro de Formação do Educador (CEFE) "Professor Leny Bevilacqua": http:// www.sjc.sp.gov.br/secretarias/educacao_cidadania/cefe.aspx

\section{DADOS DAS AUTORAS}

\section{ERIKA PASTORELLI POCKER}

Mestradanda em Educação na Universidade de Taubaté. Diretora da Escola Pública Federal Marechal do Ar Casimiro Montenegro Filho. Taubaté/SP - Brasil. erikapocker@outlook.com

\section{ANA MARIA Gimenes Corrêa CALIL}

Doutora em Psicologia da Educação pela Pontifícia Universidade Católica de São Paulo. Professora da Universidade de Taubaté. Taubaté/SP - Brasil. ana.calil@unitau.br

Submetido em: 25-1-2017

Aceito em: 1-9-2017 